\title{
Editorial: Herbicide Resistance in Weeds: Early Detection, Mechanisms, Dispersal, New Insights and Management Issues
}

\author{
Ilias Travlos ${ }^{1 *}$, Rafael de Prado ${ }^{2}$, Demosthenis Chachalis ${ }^{3}$ and Dimitrios J. Bilalis ${ }^{1}$ \\ ${ }^{1}$ Laboratory of Agronomy, Department of Crop Science, Agricultural University of Athens, Athens, Greece, ${ }^{2}$ Department of \\ Agricultural Chemistry and Edaphology, University of Córdoba, Córdoba, Spain, ${ }^{3}$ Benaki Phytopathological Institute, Athens, \\ Greece
}

Keywords: herbicide resistance, weeds, new cases, mechanisms, dispersal, fitness cost

Editorial on the Research Topic

Herbicide Resistance in Weeds: Early Detection, Mechanisms, Dispersal, New Insights and Management Issues

Herbicides are considered to be among the most widely used plant protection products. Weed management is mainly based on herbicide applications, partially due to their rapid action, high efficacy, and low cost (De Prado et al., 2004; Travlos et al., 2017). Chemical weed control by means of the use of herbicides was broadly adopted in many agricultural areas, reducing the labor costs and the mechanical means dependence. For instance, in USA, herbicide usage in 1950 accounted only for $5-10 \%$ of the total area in cotton, maize, and wheat fields, whereas in 1980 the corresponding value was 90-99\% (Fernandez-Cornejo et al., 2014).

However, this tremendous over-reliance on herbicides along with the absence of any preventive

Edited and reviewed by: Mark A. Elgar,

The University of Melbourne, Australia

*Correspondence: Ilias Travlos travlos@aua.gr

Specialty section:

This article was submitted to Agroecology,

a section of the journal

Frontiers in Ecology and Evolution

Received: 15 April 2020

Accepted: 08 June 2020

Published: 24 July 2020

Citation:

Travlos I, de Prado R, Chachalis D and Bilalis DJ (2020) Editorial: Herbicide Resistance in Weeds: Early Detection, Mechanisms, Dispersal, New Insights and Management Issues.

Front. Ecol. Evol. 8:213. doi: 10.3389/fevo.2020.00213 or other cultural practices resulted in the evolution and spread of herbicide-resistant weeds (De Prado et al., 2000; Travlos and Chachalis, 2010, 2013; Travlos et al., 2018). However, any solution should first be based on the accurate identification of the problem, the current status and the deep knowledge on several key aspects. Therefore, the main objectives of this Research Topic was not only to present the most advanced research dealing with the management of resistant weeds, but also to attract new insights on biology, ecology, physiology, genetics and epigenetics, population dynamics, mechanisms, and dispersal of the resistant weeds.

\section{HERBICIDE RESISTANCE: STATUS, NEW CASES, AND MECHANISMS}

Unfortunately, the number of resistant weed biotypes keeps increasing at a worrying rate, while climate change along with new cropping systems pose new challenges (Heap, 2020). New cases of herbicide resistant weeds are recorded and the involvement of several mechanisms is systematically studied. Tahmasebi et al. characterized the resistance to diquat/paraquat (bipyridiliums) in an Epilobium ciliatum biotype collected in an olive orchard from Chile. Physiological and biochemical studies determined the resistance to diquat of the R1 biotype, which was due to impaired translocation. Oliveira et al. investigated the genetic control of mesotrione resistance in an Amaranthus tuberculatus population from USA and the results of this study aid to understand the genetics and inheritance of a non-target-site resistance to HPPD inhibitor herbicides. Panozzo et al. studied the cross-resistance pattern, the resistance mechanism and the fitness costs of 
an ALS inhibiting Echinochloa crus-galli population and reported for the first time the Ala-122-Asn amino-acid change in the ALS gene that confers high levels of cross-resistance to several ALS inhibitors. Bracamonte, Fernández-Moreno, Bastida, et al. reported the first case of herbicide resistance in Cuba. Their results revealed a glyphosate resistant (GR) population of Chloris elata, with its resistance involving both non-target site and target-site mechanisms. This pattern of two different resistance mechanisms (both target-site and non-target site) was also reported for GR populations of Lolium perenne and $L$. multiflorum by Fernandez-Moreno, Alcántara-de la Cruz et al. Additionally, Torra et al. also reported two 2,4-D non-target site resistance mechanisms (reduced translocation and enhanced metabolism) being present in two Papaver rhoeas populations. The involvement of other mechanisms is also common in several herbicide resistant weed species. Brunharo and Hanson found that vacuolar sequestration is involved in the resistance to paraquat in a population of $L$. perenne spp. multiflorum. Yanniccari et al. found that the over-expression of EPSPS appears to be the main mechanism responsible for resistance to glyphosate in a $L$. perenne population from Argentina. This over-expression was something previously reported by Tani et al. (2016). Fernandez-Moreno, Bastida et al. confirmed a reduced glyphosate uptake and translocation as being the main mechanism involved in glyphosate resistance in a GR biotype of $L$. rigidum. The objective of the study conducted by Nakka et al. was to investigate the mechanism of HPPD-inhibitor (mesotrione) resistance in A. palmeri. Their findings revealed that mesotrione resistance in $A$. palmeri is conferred primarily by rapid detoxification (non-target-site based) of mesotrione; additionally, increased HPPD gene expression (target-site based) also contributes to the resistance mechanism in the evolution of herbicide resistance in this naturally occurring weed species. Furthermore, Iwakami et al. found that seven of the nine accessions of Alopecurus aequalis grown in a single wheat field survived application of standard field rates of thifensulfuronmethyl, indicating that severe infestations likely result from herbicide resistance. Resistant plants carry a mutation in either the ALS1 or ALS2 gene, with all mutations causing an amino acid substitution at the Pro197 residue, which is known to confer SU resistance. Transcription of each ALS gene copy was confirmed by reverse transcription PCR, supporting involvement of these mutations in SU resistance. The information on the copy number and full-length sequences of $A L S$ genes in A. aequalis will aid future analysis of the mechanism of resistance.

Among the herbicides, glyphosate is the most widely used globally for the control of weeds in both agricultural and non-agricultural areas for more than three decades (Andert et al., 2019). The worldwide market of this active ingredient is continuously increasing (annually higher than 5 billion $e$ ), with the overall consumption reaching more than 0.8 million tons per year and the annual production accounting for more than 1.1 million tons per year. It has to be noted that glyphosate represents $12 \%$ of the overall pesticide market globally by 2012 (Székács and Darvas, 2018). It is also noticeable that in countries like Germany, glyphosate market is large and the sales of glyphosatebased products covers more than one third of the total herbicide amount (Steinmann et al., 2012). The overreliance on this herbicide has resulted in the development of several cases of weeds resistant to glyphosate (Feng et al., 2004; Vidal et al., 2007; Travlos and Chachalis, 2010; Gonzalez-Torralva et al., 2012). Currently, there are 48 glyphosate-resistant species worldwide (Heap, 2020). The evolution of resistance to glyphosate is evolving at a steady pace (Heap and Duke, 2018) and results in low efficacy, with the weed management costs significantly increased. Therefore, it is rather anticipated that more and more researchers from different countries study the potential resistance of several weeds to glyphosate and the mechanisms involved. For instance, Karn and Jaseniuk investigated the frequency of targetsite mutations conferring resistance to glyphosate combined with the frequency of resistant individuals in $14 \mathrm{~L}$. perenne populations. Seven unique alleles were detected at codon site 106 , four of which have been previously shown to confer targetsite-based resistance to glyphosate. Four different resistance alleles were detected, indicating that resistance to glyphosate has evolved multiple times in the region. In two populations, no EPSPS mutations were detected despite the presence of resistant plants, strongly suggesting that non-target-site-based mechanisms confer resistance to glyphosate in these populations. It is likely that resistance to glyphosate in these 14 California populations of $L$. perenne derives from at least five evolutionary origins, indicating that adaptive traits can evolve repeatedly over agricultural landscapes.

Bracamonte, Fernández-Moreno, Barro et al. studied the resistance level and mechanisms of different Parthenium hysterophorus accessions (three collected in Cuba and four collected in the Dominican Republic) under greenhouse and laboratory conditions. Results have shown that high glyphosate resistance values were determined by the number of defense mechanisms (target-site and non-target-site resistance) possessed by the different $P$. hysterophorus accessions. Alcántara-de la Cruz, Rojano-Delgado et al. studied three glyphosateresistant populations of Lepthochloa virgate collected in citrus orchards from Mexico were studied in terms of their resistance mechanisms. It was shown that the three resistant $L$. virgata populations show reduced absorption and translocation of ${ }^{14} \mathrm{C}$ glyphosate. Moreover, a mutation and an enhanced EPSPS basal activity at target-site level confers higher resistance to glyphosate. In the first report of Bidens pilosa populations with glyphosate resistance, Alcantara-de la Cruz, Fernández-Moreno et al. revealed that target-site mutations associated with a reduced translocation were responsible for the higher glyphosate resistance in the one resistant population. The low-intermediate resistance of the other resistant population was mediated by reduced translocation.

Moreover, studies on interactions and effects of soil parameters, climatic conditions and cultural practices on herbicide resistance of weeds are becoming more common (Kleinman et al., 2015; Robinson et al., 2015; Matzrafi et al., 2016). In another study, Matzrafi, Shaar-Moshe et al. studied the potential role of temperature on chemical control and particularly pinoxaden resistance in Brachypodium hybridum. It was suggested that elevated activity of enzymatic processes at high-temperature may induce rapid and efficient 
pinoxaden metabolism leading to temperature-dependent herbicide resistance.

\section{POTENTIAL DISPERSAL, EARLY DETECTION AND FITNESS COST OF HERBICIDE RESISTANT WEED BIOTYPES}

Regarding the potential dispersal of herbicide resistant biotypes, special attention should be paid to the early detection of herbicide-resistance which could mitigate the spread of the problem (Schulz et al., 2014). The first step to preventing herbicide resistance and efficiently managing is early detection. Patterson et al. proposed a KASP genotyping method to identify northern watermilfoil (Myriophyllum sibiricum Kom.), Eurasian watermilfoil (M. spicatum L.), and their interspecific hybrids (M. spicatum $\times$ M. sibiricum). Accurate and rapid identification of hybrid individuals within populations is very important due to their usually higher fitness and reduced sensitivity to some commonly used herbicides. Lakes with complex species distribution dynamics, such as a low proportion of hybrids, are where herbicide application must be carefully chosen so as not to select for the more vigorous and less herbicide-sensitive hybrid individuals. Matzrafi, Herrmann et al. proposed a toolbox based on hyperspectral technologies and data analyses aimed to predict A. palmeri seed germination and response to the herbicide trifloxysulfuron-methyl. Sensitive and resistant plants were identified with high degrees of accuracy from leaf hyperspectral reflectance profiles acquired prior to herbicide application and thus more targeted control methods can be developed.

Herbicide resistance may or may not constitute a competition penalty in the resistant populations (Vila-Aiub et al., 2009; Travlos, 2013; Yanniccari et al., 2016). Development of integrated management strategies for herbicide-resistant weeds clearly requires an understanding of population dynamics and potential impacts of the resistant biotypes. Therefore, research on the relative competitiveness of herbicide-resistant and -susceptible biotypes is crucial. Fernández-Escalada et al. studied the genetics in Amaranthus palmeri and particularly the pleiotropic effects of EPSPS transcript abundance and of glyphosate application on the aromatic amino acid and branched chain amino acid synthesis pathways. Their findings suggest that the high copy number variation of EPSPS in A. palmeri GR populations has no major pleiotropic effect on the expression of amino acid biosynthetic genes. This finding is probably related to the limited fitness cost associated with EPSPS copy number variation in A. palmeri. Glyphosate resistant populations of L. perenne and L. multiflorum studied by Fernández-Moreno, Alcántara-de la Cruz et al. probably had a fitness cost and consequently a competitive disadvantage.

Frenkel et al. studied the effects of environmental conditions on the fitness penalty in herbicide resistant Brachypodium hybridum. The application of PSII inhibitors may have created selective pressure toward TSR dominancy; termination of herbicide application gave an ecological advantage to $S$ plants, creating changes in the composition of the seed bank. Alternatively, the high radiation intensities found in the Mediterranean-like climate may reduce the fitness penalty associated with TSR. Our results may suggest that by integrating non-herbicidal approaches into weed-management programs, we can reduce the agricultural costs associated with herbicide resistance. Zangeneh et al. evaluated germination and seedling emergence characteristics of three rigid ryegrass biotypes (one susceptible and two resistant populations with different mutations, namely Ile 1781 Leu and Ile 2041 Asn) and of competition between this weed and wheat. There was no apparent fitness penalty associated to ACCaseinhibitor resistance, while different mutations may impose different competitive ability and therefore require case-specific management strategies.

Osipitan and Dille assessed the fitness cost of glyphosate resistance compared to susceptibility in six kochia populations at different life history stages, namely rate of seed germination, increase in plant height, days to flowering, biomass accumulation at maturity, and fecundity. Of the life history stages measured, fitness differences between the GR and GS kochia populations were consistently found in their germination characteristics. The GR kochia showed reduced seed longevity, slower germination rate, and less total germination than the GS kochia. In the field, increases in plant height, biomass accumulation, and fecundity were not clearly different between GR and GS kochia populations (irrespective of neighbor density).

Matzrafi, Gerson et al. showed that individuals of L. rigidum resistant to ACCase inhibitors had significantly lower grain weight and early vigor compared with the sensitive ones. The study conducted by Keshtkar et al. was the first evaluation of potential fecundity and vegetative fitness cost of a non-target site resistant black-grass (Alopecurus myosuroides) population. According to the results, the resistant black-grass has no fitness cost and probably it will persist in the field even in the cessation of fenoxaprop-P-ethyl. The different fitness between resistant and susceptible phenotypes of Echinochloa crus-galli reported by Panozzo et al. suggests that keeping the infestation density as low as possible can increase the reproduction success of the susceptible phenotype and therefore contribute to lowering the ratio between resistant and susceptible alleles.

\section{WHAT ABOUT MANAGEMENT?}

Studies like the above-mentioned ones on fitness cost evaluation could provide some valuable information that will be useful for predicting the evolutionary dynamics of resistant populations and consequently for developing appropriate resistance management strategies. In fact, the confirmed presence of resistant biotypes with a fitness penalty may provide an opportunity to minimize or reverse herbicide resistance evolution through the implementation of effective and integrated weed management practices.

Küpper et al. studied eight different populations of Amaranthus palmeri by analyzing patterns of phylogeography and diversity to ascertain whether resistance evolved independently or spread from outside to an Arizona locality. Their data confirmed that both scenarios were possible, 
highlighting the complicated nature of the problem and underlying the need of integrated weed management and seed dispersal prevention. Ganie and Jhala evaluated the interaction of glufosinate plus 2,4-D and/or dicamba for control of GR giant ragweed, and determined their effect on GR giant ragweed density, biomass, maize injury, and yield. Their results revealed that tank-mixing glufosinate with 2,4-D or dicamba showed an additive effect and will be an additional tool with two effective modes of action for the management of GR giant ragweed in maize. Fernández-Moreno, Bastida et al. indicated that herbicide applications at the later growth stage tended to be less effective in terms of immediate effects on population size than earlier applications, and that only in some cases, the removal of at least $85 \%$ of the GR biotype of L. rigidum was achieved. However, with few exceptions, the alternative treatments tested appeared to be highly effective in reducing the seed bank irrespective of the growth stage. Chahal et al. showed that the effective control of multiple herbicide-resistant A. palmeri can be achieved with PRE followed by POST programs that include herbicides with overlapping residual activity to maintain season-long control. Barnes et al. evaluated and proposed several preplant and post-emergence applications of various herbicides for the efficient control of GR Ambrosia artemisiifolia in glufosinate-resistant soybean.

Consequently, alternative herbicides can be used (alone, in mixtures or in sequence) in order to control the herbicide resistant weeds. Unfortunately, we can't rely on many new herbicide discoveries since developing and registering a new herbicide could cost more than 300 million dollars (Beckie et al., 2019). Globally, there is also an increasing demand for a reduction in herbicides use and dependence (Böcker et al., 2018) and therefore, the role of non-chemical approaches is crucial. Such practices could favor the herbicide sensitive weed biotypes and significantly reduce the selection pressure needed for herbicide resistance evolution. Crop rotation, mulches and

\section{REFERENCES}

Alonso-Ayuso, M., Gabriel, J. L., Hontoria, C., Ibáñez, M. Á., and Quemada, M. (2020). The cover crop termination choice to designing sustainable cropping systems. Eur. J. Agron. 114:126000. doi: 10.1016/j.eja.2020. 126000

Andert, S., Mutz, J. E., Wiese, A., de Mol, F., Steinmann, H. H., and Gerowitt, B. (2019). Farmers' statements are reliable - Comparing two different data sources about glyphosate use in Germany. Crop Prot. 124:104876. doi: 10.1016/j.cropro.2019.104876

Beckie, H. J., Ashworth, M. B., and Flower, K. C. (2019). Herbicide resistance management: recent developments and trends. Plants 8:161. doi: 10.3390/plants8060161

Böcker, T., Britz, W., and Finger, R. (2018). Modelling the effects of a glyphosate ban on weed management in silage maize production. Ecol. Econ. 145, 182-193. doi: 10.1093/erae/jby050

Bottrill, D., Ogbourne, S. M., Citerne, N., Smith, T., Farrar, M. B., Hu, H. W., et al. (2020). Short-term application of mulch, roundup and organic herbicides did not affect soil microbial biomass or bacterial and fungal diversity. Chemosphere 244:125436. doi: 10.1016/j.chemosphere.2019.125436

Dayan, F. E. (2019). Current status and future prospects in herbicide discovery. Plants 8:341. doi: 10.3390/plants8090341 cover crops, biological and natural herbicides are often very effective tools for both the pro- or the re-active resistance management (Radhakrishnan et al., 2018; Alonso-Ayuso et al., 2020; Bottrill et al., 2020). Cultural practices like false seedbed can be also included in integrated weed management programs in several annual crops (Travlos et al., 2020), while decision support systems (DSS) can provide information regarding weed seedbank dynamics in the soil in order to suggest management options (both chemical and non-chemical) not only within a single period but also in a rotational view (Kanatas et al., 2020). Under this concept, the emergence and integration of new weed management tools is imperative (Dayan, 2019). In conclusion, it could be said that herbicide resistance is a reality; however, the systematic research (part of which was presented in this Research Topic) allows us to remain optimist for an effective integrated and sustainable weed management. Such a sustainable weed management and prevention of herbicide resistance should be based on both agronomy and weed science and certainly on a sound knowledge of biology, ecology, physiology, genetics and epigenetics, population dynamics, mechanisms and dispersal of the resistant weeds.

\section{AUTHOR CONTRIBUTIONS}

All authors listed have made a substantial, direct and intellectual contribution to the work, and approved it for publication.

\section{ACKNOWLEDGMENTS}

We are grateful for the support of the entire editorial board at Frontiers in Ecology and Evolution and Frontiers in Plant Science. Thanks also to the scores of peer reviewers that gave of their time and efforts to ensure that the manuscripts in this issue were strengthened via their insights.
De Prado, R., Gonzalez-Gutierez, J., Menendez, J., Gasquez, J., Gronwald, J. W., and Gimenez-Espinosa, R. (2000). Resistance to acetyl CoA carboxylaseinhibiting herbicides in Lolium multiflorum. Weed Sci. 48, 311-318. doi: 10.1614/0043-1745(2000)048(0311:RTACCI)2.0.CO;2

De Prado, R., Osuna, M. D., and Fischer, A. J. (2004). Resistance to ACCase inhibitor herbicides in a green foxtail (Setaria viridis) biotype in Europe. Weed Sci. 52, 506-512. doi: 10.1614/WS-03-097R

Feng, P. C. C., Tran, M., Chiu, T., Sammons, R. D., Heck, G. R., and Cajacob, C. A. (2004). Investigations into glyphosate-resistant horseweed (Conyza canadensis): retention, uptake, translocation, and metabolism. Weed Sci. 52, 498-505. doi: 10.1614/WS-03-137R

Fernandez-Cornejo, J., Wechsler, S. J., Livingston, M., and Mitchell, L. (2014). Genetically Engineered Crops in the United States. Washington, DC: U. S. Department of Agriculture-Economic Research Service.

Gonzalez-Torralva, F., Gil-Humanes, J., Barro, F., Brants, I., and de Prado, R. (2012). Target site mutation and reduced translocation are present in a glyphosate-resistant Lolium multiflorum Lam. biotype from Spain. Plant Physiol. Biochem. 58, 16-22. doi: 10.1016/j.plaphy.2012.06.001

Heap, I. (2020). The International Survey of Herbicide Resistant Weeds. Available online at: www.weedscience.org (accessed January 18, 2020)

Heap, I., and Duke, S. O. (2018). Overview of glyphosate-resistant weeds worldwide. Pest Manag. Sci. 74, 1040-1049. doi: 10.1002/ps.4760 
Kanatas, P., Travlos, I. S., Gazoulis, I., Tataridas, A., Tsekoura, A., and Antonopoulos, N. (2020). Benefits and limitations of Decision Support Systems (DSS) with a special emphasis on weeds. Agronomy 10:548. doi: 10.3390/agronomy10040548

Kleinman, Z., Ben-Ami, G., and Rubin, B. (2015). From sensitivity to resistance factors affecting the response of Conyza spp. to glyphosate. Pest Manage. Sci. 72, 1681-1688. doi: 10.1002/ps.418

Matzrafi, M., Seiwert, B., Reemtsma, T., Rubin, B., and Peleg, Z. (2016). Climate change increases the risk of herbicide-resistant weeds due to enhanced detoxification. Planta 244, 1217-1227. doi: 10.1007/s00425-016-2577-4

Radhakrishnan, R., Alqarawi, A. A., and Abd_Allah, E. F. (2018). Bioherbicides: current knowledge on weed control mechanism. Ecotoxicol. Environ. Safety 158, 131-138. doi: 10.1016/j.ecoenv.2018.04.018

Robinson, M. A., Letarte, J., Cowbrough, M. J., Sikkema, P. H., and Tardif, F. J. (2015). Winter wheat (Triticum aestivum L.) response to herbicides as affected by application timing and temperature. Can. J. Plant Sci. 95 325-333. doi: 10.4141/cjps-2014-109

Schulz, A., Mathiassen, S. K., and de Mol, F. (2014). Approaches to early detection of herbicide resistance in Apera spica-venti regarding intra- and inter-field situations. J Plant Dis. Prot. 121, 138-148. doi: 10.1007/BF03356502

Steinmann, H. H., Dickeduisberg, M., and Theuvsen, L. (2012). Uses and benefits of glyphosate in German arable farming. Crop Prot. 42, 164-169. doi: 10.1016/j.cropro.2012.06.015

Székács, A., and Darvas, B. (2018). Re-registration challenges of glyphosate in the European Union. Front. Environ. Sci. 6:78. doi: 10.3389/fenvs.2018.00078

Tani, E., Chachalis, D., Travlos, I. S., and Bilalis, D. (2016). Environmental conditions influence induction of key ABC-Transporter genes affecting glyphosate resistance mechanism in Conyza canadensis. Int. J. Mol. Sci. 17:342. doi: 10.3390/ijms17040342

Travlos, I. S. (2013). Competition between ACC-inhibitor resistant and susceptible sterile wild oat (Avena sterilis L.) biotypes. Weed Sci. 61, 26-31. doi: 10.1614/WS-D-12-00065.1

Travlos, I. S., and Chachalis, D. (2010). Glyphosate-resistant hairy fleabane (Conyza bonariensis) is reported in Greece. Weed Technol. 24, 569-573. doi: 10.1614/WT-D-09-00080.1

Travlos, I. S., and Chachalis, D. (2013). Assessment of glyphosate-resistant horseweed (Conyza canadensis L. Cronq.) and fleabane (Conyza albida Willd. ex Spreng) populations from perennial crops in Greece. Int. J. Plant Prod. 7, 665-676. doi: 10.22069/ijpp.2013.1263

Travlos, I. S., Cheimona, N., and Bilalis, D. (2017). Glyphosate efficacy of different salt formulations and adjuvant additives on various weeds. Agronomy 7:60 doi: 10.3390/agronomy7030060

Travlos, I. S., Cheimona, N., De Prado, R., Jhala, A. J., Chachalis, D., and Tani, E. (2018). First case of glufosinate-resistant rigid ryegrass (Lolium rigidum Gaud.) in Greece. Agronomy 8:35. doi: 10.3390/agronomy80 40035

Travlos, I. S., Gazoulis, I., Kanatas, P., Tsekoura, A., Zannopoulos, S., and Papastylianou, P. (2020). Key factors affecting weed seeds' germination, weed emergence, and their possible role for the efficacy of false seedbed technique as weed management practice. Front. Agron. 2:1. doi: 10.3389/fagro.2020. 00001

Vidal, R. A., Trezzi, M. M., De Prado, R., Ruiz-Santaella, J. P., and Vila-Aiub, M. (2007). Glyphosate resistant biotypes of wild poinsettia (Euphorbia heterophylla L.) and its risk analysis on glyphosate-tolerant soybeans. J. Food Agric. Environ. 5, 265-269. doi: 10.1234/4.2007.1014

Vila-Aiub, M. M., Neve, P., and Powles, S. B. (2009). Fitness costs associated with evolved herbicide resistance alleles in plants. New Phytol. 184, 751-767. doi: 10.1111/j.1469-8137.2009.03055.x

Yanniccari, M., Vila-Aiub, M., Istilart, C., Acciaresi, H., and Castro, M. A. (2016). Glyphosate resistance in perennial ryegrass (Lolium perenne L.) is associated with a fitness penalty. Weed Sci. 64, 71-79. doi: 10.1614/WS-D-1500065.1

Conflict of Interest: The authors declare that the research was conducted in the absence of any commercial or financial relationships that could be construed as a potential conflict of interest.

Copyright (c) 2020 Travlos, de Prado, Chachalis and Bilalis. This is an open-access article distributed under the terms of the Creative Commons Attribution License (CC $B Y)$. The use, distribution or reproduction in other forums is permitted, provided the original author(s) and the copyright owner(s) are credited and that the original publication in this journal is cited, in accordance with accepted academic practice. No use, distribution or reproduction is permitted which does not comply with these terms. 